\title{
Zero-contrast percutaneous coronary intervention of saphenous vein graft in a patient with chronic renal failure
}

\author{
Jerzy Sacha, Piotr Feusette \\ Department of Cardiology, University Hospital, University of Opole, Opole, Poland
}

Adv Interv Cardiol 2018; 14, 3 (53): 309-311

DOI: https://doi.org/10.5114/aic.2018.78337

Zero-contrast percutaneous coronary intervention $(\mathrm{PCl})$ is a new technique for preventing contrast-induced nephropathy (CIN) [1]. Recently, some complex procedures have been performed with this approach, including $\mathrm{PCl}$ of the left main [2], chronic total occlusion [live case at CTO Summit 2017, New York] and intervention of calcified lesions using rotational atherectomy [3]. Herein, we present a case of zero-contrast $\mathrm{PCl}$ of a saphenous vein graft (SVG) in a patient with chronic renal failure (estimated glomerular filtration rate, eGFR: $25.84 \mathrm{ml} / \mathrm{min} / 1.73 \mathrm{~m}^{2}$ ) who was admitted to our hospital due to non-ST-segment elevation myocardial infarction. Coronary angiography revealed: chronic occlusions of right coronary artery (RCA), left anterior descending artery (LAD) and SVG to obtuse marginal branch (OM); critical stenosis of OM; significant stenosis of SVG-RCA (Figure $1 \mathrm{~A}$ ); and patent left internal mammary artery graft to LAD. First, urgent $\mathrm{PCl}$ of the $\mathrm{OM}$ was carried out, then 4 days later we performed $\mathrm{PCl}$ of the SVG-RCA. However, in order to protect renal function the second intervention was done without contrast administration. After careful analysis of previous angiograms and all surrounding anatomical details, an MPA guiding catheter (which best fitted the anatomy of the graft) was placed into the ostium of the SVG-RCA. To engage it, we followed a surgical clip within the occluded SVG-OM which superimposed on the ostium of the SVG-RCA, and the correct catheter position was confirmed by introducing a Sion Blue guidewire (Asahi) to the distal portion of the RCA (Figure 1 B). Then intravascular ultrasound examination (IVUS) identified the lesion in reference to overlying ribs. Once an embolic protection device, Spider FX $4.0 \mathrm{~mm}$ (Medtronic), had been placed distally to the lesion, a repeated IVUS examination determined proximal and distal landing zones for stent implantation in relation to the ribs and protection device (Figures 1 C, D).
A drug-eluting stent, Orsiro 4.0/18 mm (Biotronik), was implanted according to the position of ribs (Figure $1 \mathrm{E}$ ) and post-dilatation with a balloon Trek $4.0 / 20 \mathrm{~mm}$ was performed. The IVUS examination confirmed good stent expansion and no edge dissection. After removal of the protection system, one single injection of $5 \mathrm{ml}$ of contrast (Visipaque, GE Healthcare) was done in order to document the final result and lack of complications (Figure $1 \mathrm{~F}$ ). The whole procedure lasted $50 \mathrm{~min}$ and the total radiation dose was $1418 \mathrm{mGy}$. Following $\mathrm{PCl}$, the renal function remained stable with no decrease in eGFR.

This case shows that zero-contrast $\mathrm{PCl}$ is safe and feasible even for SVG. During such procedures, it is crucial to seek landmarks which may guide the operation, and the most common landmarks are overlying ribs, intercostal spaces and calcified vessels. However, in patients after coronary artery bypass grafting, surgical clips within grafts may also guide the procedure. In this particular case, the clip of another graft superimposed on the ostium of the SVG-RCA and directed the catheter engagement. In addition, the overlying rib helped in positioning the stent (Figure $1 \mathrm{E}$ ). It should be noted that due to the heart motion and respiration, the landing zones are moving in reference to the ribs; therefore, one should carefully analyze the character of these movements and accordingly cover these "moving landing zones" with the stent. Usually, we do not stop respiration during stent implantation since a deep inspiration may significantly change the position of the whole system. To facilitate such a procedure, we have recently described the marking wire technique for zero-contrast PCl [4].

Indeed, not all lesions may be treated without contrast, and particularly bifurcation lesions are the most challenging ones. However, as we have recently shown, even complex left main $\mathrm{PCl}$ may be performed with ze-

Corresponding author:

Jerzy Sacha MD, PhD, Department of Cardiology, University Hospital, University of Opole, Al. Witosa 26, 45-401 Opole, Poland, phone: +48 7745206 60, +48600273 616, fax: +48 7745206 99, e-mail: sacha@op.pl

Received: 18.03 .2018 , accepted: 8.04.2018. 

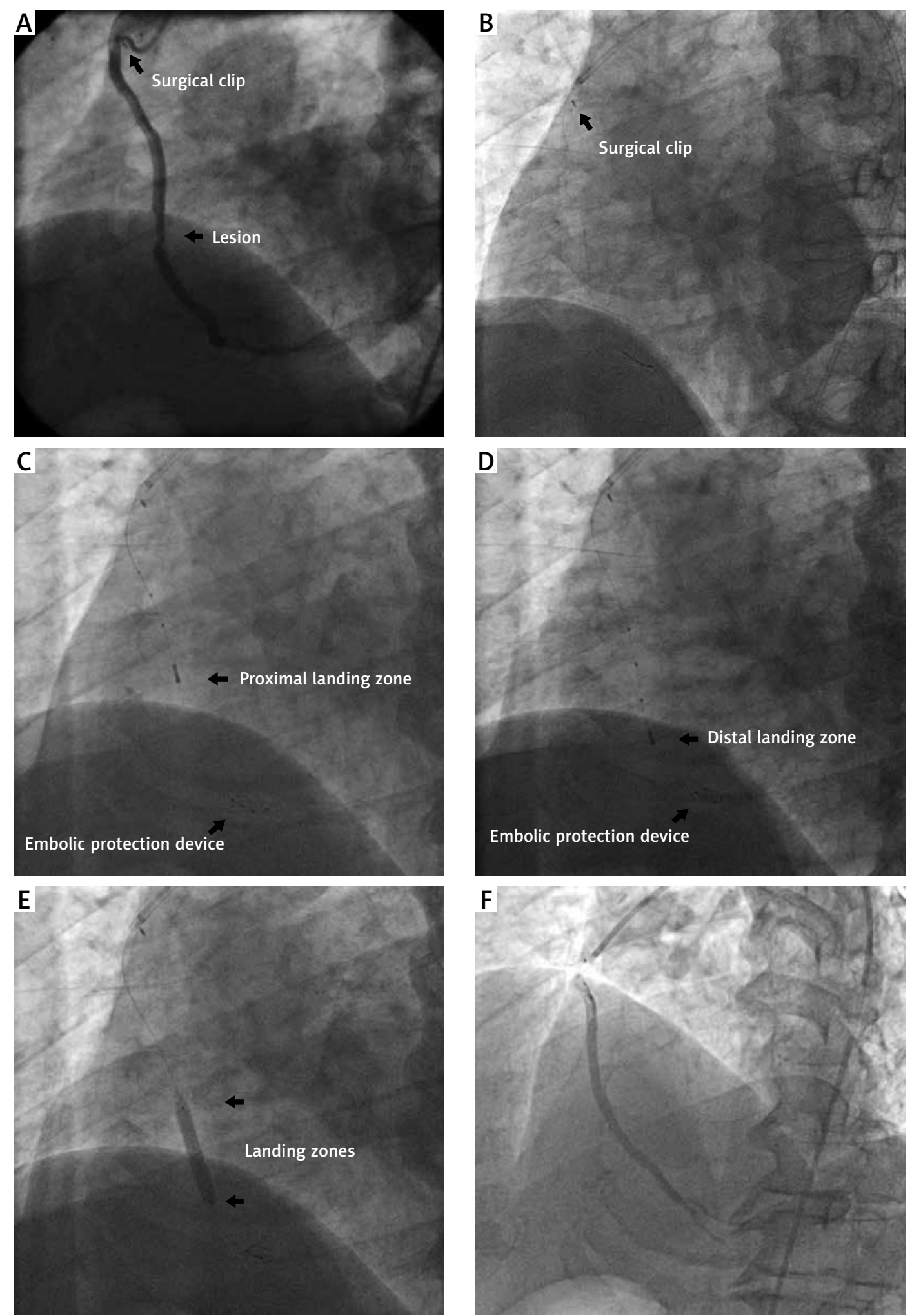

Figure 1. A - Angiography reveals $80 \%$ stenosis within the central part of the saphenous vein graft (SVG) to the right coronary artery (RCA) (upper arrow indicates a surgical clip of another graft which superimposes on the ostium of the SVG-RCA), B - MPA guiding catheter has been engaged at the ostium of the SVG-RCA according to the position of the overlying surgical clip and the correct catheter placement was confirmed by introducing the guidewire to the vessel, C - proximal landing zone is identified by intravascular ultrasound (IVUS) in reference to the ribs, $\mathbf{D}$ - distal landing zone is determined at the lower edge of the rib, $\mathbf{E}$ - the stent is implanted in reference to the ribs, $\mathrm{F}$ - Single contrast injection documents the final $\mathrm{PCl}$ result 
ro-contrast technique [2]. In this approach, one of the most important points is to insert guidewires in a proper way to avoid vessel perforation - if there is any doubt, a small amount of contrast should be injected to exclude complications.

This case and other reports show that zero-contrast interventions are promising preventative measures against CIN and they are not associated with any additional costs except those associated with IVUS examination [1-3]. However, the question arises whether the no-contrast technique presents any advantage over ultra-low contrast usage. Therefore, further development of the method and confirmative studies are needed to prove the safety and efficacy of this approach.

\section{Conflict of interest}

The authors declare no conflict of interest.

\section{References}

1. Ali ZA, Karimi Galougahi K, Nazif T, et al. Imaging- and physiology-guided percutaneous coronary intervention without contrast administration in advanced renal failure: a feasibility, safety, and outcome study. Eur Heart J 2016; 37: 3090-5.

2. Sacha J, Feussette P. How should I treat unprotected LM stenosis in a patient with ACS who develops a severe contrast-induced nephropathy after coronary angiography? https://www. pcronline.com/Cases-resources-images/Cases/EIJ-HSIT/Treatment-strategy-for-left-main-stenosis-in-patient-with-CIN?auth=true\#comments_area (Published, 06 December 2017).

3. Karimi Galougahi K, Mintz GS, Karmpaliotis D, Ali ZA. Zero-contrast percutaneous coronary intervention on calcified lesions facilitated by rotational atherectomy. Catheter Cardiovasc Interv 2017; 90: E85-9.

4. Sacha J. Marking wire technique for zero-contrast percutaneous coronary interventions. Adv Interv Cardiol 2018; 14: 204-5. 